The Making of the Broads

A Reconstruction of their Origin in the Light of New Evidence. By Dr. J. M. Lambert, J. N. Jennings, C. T. Simith, Charles Green and J. N. Hutchinson. (R.G.S. Research Series, No. 3.) Pp. vii $+153+7$ plates. (London: Royal Geographical Society, and John Murray (Publishers), Ltd., 1960.) $25 s$.

THOUSANDS of people know the "Broads". What pleasant memories they evoke--lovely country, interesting bird life, good sailing, joyous parties aboard a motor launch! But how many holiday makers have ever asked themselves how these large lakes were formed? Clearly they are different from any other sheets of water in Britain; How did they come into being? Much research has been devoted to this problem of recent years, and it has been attacked from various points of view-geological, historical, philological, botanical, etc. As the outcome of these investigations it would seem that everything now points to the conclusion that the broads resulted from peat diggings during the Middle Ages. Somewhere about the fourteenth century slight land sinkage, perhaps combined with a tidal break-through such as occurred a few years ago, flooded the peat workings, and this flood water could not drain away owing to the row lower level of the land relative to the sea. The broads, then, wore turbaries. It can be shown that, as should be the case, they have vertical peat sides, nowadays somewhat masked by subsequent slight infilling of silt and mud, and we can sometimes also notice transverse baulks of undug peat forming ridgos, to-day only just covered by the water ; there are also islands of peat similarly only just below water-level. Historical records show that vast peat workings did exist in this area in the carly Middle Ages, and the method of working can be determined. Fairly suddenly these methods changed, and much of the peat exploitation ceased. This would seem to correspond with the flooding of the workings.

It must be remembered that transport in the eleventh, twelfth and thirteenth centuries was difficult, and little suitable fuel other than peat existed in East Anglia, which nevertheless was a well-populated part of the country. That peat digging should have existed on a large scale is not surprising. The fact of land sinkage perhaps coupled with tidal breakthroughs altered the whole picture and resulted in the broads we know to-day. So whether the holiday maker is sailing over aristocratic Ranworth or statcly Barton or proletarian. Wroxham, let him spare a moment to remember the old peat workers, his forerunners, to whose labours his present enjoyment is due.

Mulas BURKITT

Premier Colloque International de Photographie Corpuscu'aire, Strasbourg, |er au 6 Juillet, 1957 (Colloques Internationaux du Centro National do la Recherche Scientifique, No. 79.) Pp. 451. (Paris : Contre National de la Recherche Scientifique, 1958.) 5,300 francs.

T THE introduction of the photographic emulsion as a detcetor of charged particles has had an impact on physics which will be familiar to students of ovolutionary biology. We can recognize a long and rather obscure development period, a sudden emergence as a practical device, and then an explosive deployment into many fields and applications as its very adaptablo features were recognized. In about a decade a vast literature has grown around the subject of nuclear track plates which must bewilder those about to use them for the first time. Nor are there any signs that track plates have reached the final stage of the evolutionary process, namely, the slow decline and ultimate extinction in the face of the competition from newer types of charged particle detectors. This is evident from the subjects covered in this book, which is a record of the First Inter. national Conference on Purticle Track, Photography held at Strasbourg in 1957. The main aims of this conference were to examine the present state of our knowledge concerning the photographic action of charged particles, to survey the results obtained in recent years, and to seek ways of improving the emulsions to meet the changing requirements of physics and the widening fields of application. There are about fifty contributions by delegates from fourteen countries on the theory of latent image formation, the preparation, properties, processing and application of nuclear emulsions. The book is well illustrated by diagrams and photographs and provides a valuable account of the latest techniques written by experts, many of whom were pioneers in the development of track-plate photography.

D. L. Allain

\section{The Transits of Venus}

A Study of Eighteenth-Century Science. By Prof. Harry Woolf. Pp. xiii $+258+11$ plates. (Princeton, N.J. : Princeton University Press ; London : Oxford University Press, 1959.) 48s. net.

T $\mathbf{F}$ one says of this book that it is a careful and I scholarly work describing the aims and adventures of those who, in the eighteen'sh contury, tried to determine the distance of the Earth from the Sun by observations of Venus on the rare occasions when the planet was seen projected on the solar disk, one has said almost everything possible by way of general appreciation.

As a contribution to the history of astronomy this is an important work which will be useful primarily as a complete record of the hopes and fears, succosses and failures, hair-breadth escapes and solid achievement of the many scientists and travellers who took part in the observational schemes. One can, however, see more in the volume than a catalogue of historical sources. The tale, considered as a whole, shows how essentially modern the eighteenth century was, and how particularly France, Britain and Sweden could even at that time plan great scientific projects in a manner which would not be out of place to-day. The science of the seventeenth century still had recognizable roots in medievalism : that of the eighteenth looked forward with a philosophy still unchanged in our own time. It is even conceivable that we could draw a modern lesson from this record, and by the use of multiple photography of Mercury or Venus when projected on the solar disk overcome the uncertainties introduced by the indefiniteness of the solar limb in any one exposure, and reintroduce the transit method as a modern means for the determination of the solar parallax. David S. Evans

Évacuation et Récupération de la Chaleur des Réacteurs Nucléaires

Par Richard Alami et P'aul Ageron. (Introduction an Génie Nucléaire, Tome 3.) Pp. ix +246 . (Paris: Dunod, 1958.) 2,900 francs.

7 HIS, the third volume of an introduction to nuclear energy, is devoted to the removal and utilization of heat from nuclear reactors. The work 